\title{
Preparation and adsorption properties of magnetic chitosan composite adsorbent for $\mathrm{Cu}^{2+}$ removal
}

Jixiang $\mathrm{Li}^{1}$, Buqing Jiang ${ }^{1,2}$, Yi $\mathrm{Liu}^{1,2}$, Changquan $\mathrm{Qiu}^{1}$, Jiajun $\mathrm{Hu}^{2}$, Guangren Qian ${ }^{2 *}$, Wenshan $\mathrm{Guo}^{3}$, Huu Hao $\mathrm{Ngo}^{3 *}$

${ }^{1}$ Shanghai Advanced Research Institute, Chinese Academy of Science, Shanghai 201210, China

${ }^{2}$ Shanghai University, Shanghai 200444, China

${ }^{3}$ Centre for Technology in Water and Wastewater, School of Civil and Environmental Engineering, University of Technology Sydney, NSW 2007, Australia

Corresponding authors. Tel.: +86 02166137758 (G.R. Qian), +61 295142745 (Huu Hao Ngo). Email address: grqian@staff.shu.edu.cn (G.R. Qian), HuuHao.Ngo@uts.edu.au (Huu Hao Ngo).

\begin{abstract}
Water pollution caused by $\mathrm{Cu}^{2+}$ ions poses a significant threat to the ecosystem and human health, hence the development of highly cost-effective, highly operation-convenient and highly efficient natural polymer-based adsorbents is urgently needed. To overcome this serious problem, a novel cost-effective magnetic chitosan composite adsorbent ( $\mathrm{CsFeAC})$ was prepared with magnetic macroparticles and highly porous activated carbon carrier using the sol-gel method. Several methods, namely SEM, BET, FTIR, XRD, TGA and VSM, were applied to characterize the adsorbent. Batch tests were conducted to investigate $\mathrm{Cu}^{2+}$ adsorption properties of $\mathrm{CsFeAC}$ at different $\mathrm{pH}$ values, contact time, initial $\mathrm{Cu}^{2+}$ concentrations and temperatures. The adsorption fits better to the Langmuir isotherm and follows the pseudo-second-order model, suggesting that it is a monolayer adsorption and the rate-limiting step is the chemical chelating reaction. The saturated
\end{abstract}


adsorption capacity is found to be $216.6 \mathrm{mg} / \mathrm{g}$. Thermodynamics analysis suggests that the adsorption process is endothermic, with increasing entropy and spontaneous in nature. BET and XRD tests confirm that the higher specific surface area and lower crystallinity of CsFeAC significantly improve the absorption capacity and rate. FTIR spectra reveal that the amino and hydroxyl groups play an important role in the chelating adsorption. The supermagnetic property of $\mathrm{CsFeAC}$ facilitates its easy separation characteristic. Further recycling experiments show that CsFeAC still retains $95 \%$ of the original adsorption following the $5^{\text {th }}$ adsorption-desorption cycle. All these results demonstrate that $\mathrm{CsFeAC}$ is a promising recyclable adsorbent for removing $\mathrm{Cu}^{2+}$.

Keywords: $\mathrm{Cu}^{2+}$ adsorption, magnetic chitosan, activated carbon, magnetic separation

\section{Introduction}

With the rapid growth of industrialization, water pollution caused by heavy metals has become one of the most serious environmental problems, and attracted considerable attention (Zhu et al., 2012; Lara et al., 2014). $\mathrm{Cu}^{2+}$ is one of the most common heavy metal ions used in several industries, such as dyeing, copper electroplating, and petroleum refining (Wu et al., 2015; Demiral et al., 2016). To minimize the pollution caused by $\mathrm{Cu}^{2+}$ ions, the maximum contaminant level for

$\mathrm{Cu}^{2+}$ developed by Chinese Environmental Protection Agency has decreased from $1.0 \mathrm{mg} / \mathrm{L}$ of GB8978-1996 to $0.5 \mathrm{mg} / \mathrm{L}$ of GB21900-2008 for industrial effluents. To fit the increasingly stringent discharge requirements, several technologies, for example, chemical precipitation, adsorption, ionic exchange, membrane separation, etc., have been developed for removing $\mathrm{Cu}^{2+}$ (Ren et al., 2013; Zhang et al., 2008; Mi et al., 2015; Zhou et al., 2009). Of these methods, adsorption is recognized as the most effective and widely employed (Ali et al., 2007; 
Ananpattarachai et al., 2016; Luo et al., 2015). In particular, the adsorbents derived from natural biopolymers, such as chitosan, are promising due to their wide availability, biodegradability and biocompatibility (Meng et al., 2015; Nitayaphat et al., 2015; Leceta et al., 2013).

Magnetic chitosan adsorbents have been considered to be excellent candidates for heavy metals removal due to their highly chelating capability and easy magnetic separation (Xu et al., 2015). Especially, many chitosan-based adsorbents are prepared with magnetic nanoparticles for their higher specific surface area and lower internal diffusion resistance (Elwakeel et al., 2014; Nasirimoghaddam et al., 2015; Tao et al., 2016; Chen and Wang, 2011). However, magnetic nanoparticles are highly chemically active, and are easily oxidized in the air which may result in magnetism loss and aggregation (Reddy et al., 2013). These nanoparticles also cause secondary pollution to the environment due to their very minute dimensions. Conversely, the magnetic cores with larger sizes (such as macroparticles) can facilitate the magnetic separation process (Herrling et al., 2015; Wang et al., 2011). Additionally, the higher specific surface area can be obtained by loading on other porous carriers, e.g. activated carbon powder, which may provide an alternative method to improve the adsorption capacity for heavy metals removal (Liu et al., 2014; Cechinel et al., 2014). Furthermore, iron oxides are susceptible to acid conditions, which may lead to the adsorbents losing their magnetism (Wang et al., 2010). Consequently, inert coating layers are necessary to protect the magnetic cores (Huang et al., 2016; Li et al., 2012).

Based on all the above discussions, a novel magnetic chitosan composite adsorbent of chitosan/ $/ \mathrm{SiO}_{2} / \mathrm{Fe}_{3} \mathrm{O}_{4} /$ activated carbon (CsFeAC) was preferably prepared with the sol-gel method using glutaraldehyde as cross-linker in this present work. As far as we know, this is the first study to investigate a cost-effective chitosan composite adsorbent together with magnetic macroparticles 
and highly porous activated carbon for improving adsorption efficiency. The adsorbent was systemically characterized by scanning electron micrograph (SEM), Brunauer-Emmett-Teller (BET) surface area test, Laser particle size analyzer (LPSA), Fourier transform infrared (FTIR) spectra, X-ray diffraction (XRD), thermogravimetric analysis (TGA) and vibrating sample magnetometer (VSM). Batches of tests were conducted to investigate the adsorption properties of $\mathrm{CsFeAC}$ for $\mathrm{Cu}^{2+}$ removal, and the adsorption isotherm, kinetics, and thermodynamics were further analyzed. Also, the reusability of the adsorbent was examined for further application.

\section{Materials and methods}

\subsection{Materials}

Chitosan used in this study was purchased from Nan Tong Xing Cheng Biological Products Co.

Ltd. Its deacetylation degree and viscosity average molecular weight were $91 \%$ and $1.5 \times 10^{5} \mathrm{~g} / \mathrm{mol}$, respectively. Activated carbon from coal was provided by Chengde Huajing Activated Carbon Co., Ltd. Glacial acetic acid, concentrated nitric acid, $\mathrm{NaOH}, \mathrm{Na}_{2} \mathrm{EDTA}, \mathrm{Na}_{2} \mathrm{SiO}_{3} \cdot 9 \mathrm{H}_{2} \mathrm{O}, \mathrm{Fe}_{3} \mathrm{O}_{4}$, and $\mathrm{CuSO}_{4}$ were purchased from Sinopharm Chemical Reagent Co., Ltd. All the reagents used in this study are analytical grade.

\subsection{Preparation of magnetic chitosan composite adsorbent}

\subsubsection{Preparation of magnetic activated carbon composite carrier}

The activated carbon was ground to powder in a 325-mesh sieve, then activated by $1 \mathrm{M} \mathrm{HNO}_{3}$, and washed till it reached a neutral condition using distilled water. Finally, it was dried in an oven at $80{ }^{\circ} \mathrm{C}$ and stored in a desiccator for use. $3 \mathrm{~g} \mathrm{Fe}_{3} \mathrm{O}_{4}, 2 \mathrm{~g}$ pretreated activated carbon powder, and $6 \mathrm{~g} \mathrm{Na}_{2} \mathrm{SiO}_{3} \cdot 9 \mathrm{H}_{2} \mathrm{O}$ were added to $100 \mathrm{~mL}$ of distilled water. The mixture was firstly stirred for 1 hour at $80^{\circ} \mathrm{C}$. This was followed by the mixture $\mathrm{pH}$ being adjusted between 8.0 and 10.0 by 
diluting $\mathrm{HCl}$ or $\mathrm{NaOH}$ aqueous solutions, and then stirred for another 2 hours. Furthermore, the product was purified with distilled water several times to remove impurities, such as excessive activated carbon powder and $\mathrm{SiO}_{2}$, which showed no magnetism. After necessary drying at $80{ }^{\circ} \mathrm{C}$, the resultant magnetic composite carrier of FeAC was obtained.

\subsubsection{Preparation of $\mathrm{CsFeAC}$}

CsFeAC was prepared by the sol-gel method (Chen et al., 2010). The magnetic cores embedded in chitosan are magnetically activated carbon coated with silica carriers in micrometer scale. Silica coating could connect $\mathrm{Fe}_{3} \mathrm{O}_{4}$ to activated carbon and protect $\mathrm{Fe}_{3} \mathrm{O}_{4}$ particles from acidic and oxidative conditions. The larger magnetic cores (compared to nanoparticles) can promote the magnetic separation process. The presence of activated carbon can provide a larger specific surface area to load on more effective component of chitosan for removing heavy metals.

Briefly, $3 \mathrm{~g}$ chitosan was dissolved in $100 \mathrm{~mL} \mathrm{2 \%} \mathrm{(v/v)} \mathrm{of} \mathrm{glacial} \mathrm{acetic} \mathrm{acid} \mathrm{solution} \mathrm{to} \mathrm{obtain}$ $3 \%(\mathrm{w} / \mathrm{v})$ of chitosan solution, and then $3 \mathrm{~g}$ magnetic composite carrier of $\mathrm{FeAC}$ was welldispersed in the chitosan solution after 1 hour's stirring. Following this, $40 \mathrm{~mL} 2.5 \%$ of glutaraldehyde was dropped into the as-prepared chitosan mixture within $20 \mathrm{~min}$, and this was stirred for another 4 hours. Finally, the resultant black gel was formed, which was further washed with distilled water several times to remove unreacted chitosan. Then it was freeze-dried for further experiments.

\subsection{Characterization methods}

The morphologies of carriers and adsorbents were observed by SEM (S4800, Hitachi, Japan).

The particle sizes of carriers and adsorbents were measured by LPSA (Mastersizer 2000, UK).

The specific surface areas of carriers and adsorbents were determined by a BET model (TriStar 
3000 V6.08A) using low-temperature nitrogen adsorption. FTIR spectra were recorded in $\mathrm{KBr}$ disks on a FTIR spectrometer (IR Prestige-21, Shimadzu, Japan). TGA analysis was evaluated with a thermogravimetric analyzer (TGA, SDTQ600) and the TGA curve was recorded in oxygen atmosphere. The set heating program ranged from room temperature to $100^{\circ} \mathrm{C}$ at a heating rate of $10^{\circ} \mathrm{C} / \mathrm{min}$, kept isothermally for $30 \mathrm{~min}$ and heated to $800^{\circ} \mathrm{C}$ at a heating rate of $10^{\circ} \mathrm{C} / \mathrm{min}$. XRD analysis was executed using an X-ray diffractometer (Rigaku, D/Max-2500) with a scanning range of $5-90^{\circ}$. The magnetic intensity was tested on a vibrating sample magnetometer (730 $\mathrm{T}$, Lakeshoper, USA).

\subsection{Adsorption experiments}

In order to test the adsorption capacity of $\mathrm{CsFeAC}$ for $\mathrm{Cu}^{2+}$, batch experiments were carried out by adding $0.05 \mathrm{~g} \mathrm{CsFeAC}$ in $500 \mathrm{~mL} \mathrm{Cu}{ }^{2+}$ solution. The mixture was shaken in a thermostatic shaker at a speed of $200 \mathrm{rpm}$ and the supernatant was analyzed for $\mathrm{Cu}^{2+}$ concentration. The effect of $\mathrm{pH}$ was conducted at $25{ }^{\circ} \mathrm{C}$ with $\mathrm{Cu}^{2+}$ concentration of $100 \mathrm{mg} / \mathrm{L}$. The chosen initial solution $\mathrm{pH}$ was 4.0 to 6.0 with specific reference to precipitation formation when $\mathrm{pH}$ was higher than upper limit. Adjusting the solution $\mathrm{pH}$ was conducted using diluted $\mathrm{HCl}$ or $\mathrm{NaOH}$ solutions. For adsorption equilibrium experiments, the adsorption amounts were conducted at a $\mathrm{Cu}^{2+}$ concentration varying from 0 to $1000 \mathrm{mg} / \mathrm{L}$ with the $\mathrm{pH}$ remaining below 5.5 at $25^{\circ} \mathrm{C}$ for 2 hours.

For kinetic experiments, the adsorption amounts at different contact time were conducted at a $\mathrm{Cu}^{2+}$ concentration of $100 \mathrm{mg} / \mathrm{L}$ with the $\mathrm{pH} 5.5$ at $25{ }^{\circ} \mathrm{C}$. For adsorption experiments at different temperatures $\left(25,35,45\right.$ and $\left.55^{\circ} \mathrm{C}\right)$, the mixtures were conducted at $\mathrm{pH} 5.5$ with a $\mathrm{Cu}^{2+}$ concentration of $100 \mathrm{mg} / \mathrm{L}$. The concentrations of $\mathrm{Cu}^{2+}$ were determined by a microcomputer copper concentration detector (Hanna HI96747, Italy). The adsorption capacity $\mathrm{q}_{\mathrm{t}}(\mathrm{mg} / \mathrm{g}$ ) at time $\mathrm{t}$ 
was calculated according to equation (1):

$$
\mathrm{q}_{\mathrm{t}}=\left(\mathrm{C}_{0}-\mathrm{C}_{\mathrm{t}}\right) \times \mathrm{V} / \mathrm{m}(1)
$$

where $\mathrm{C}_{0}(\mathrm{mg} / \mathrm{L})$ is the initial concentration of $\mathrm{Cu}^{2+} ; \mathrm{C}_{\mathrm{t}}(\mathrm{mg} / \mathrm{L})$ is the concentration of $\mathrm{Cu}^{2+}$ at any time $\mathrm{t} ; \mathrm{V}(\mathrm{L})$ is the volume of the $\mathrm{Cu}^{2+}$ solution; and $\mathrm{m}(\mathrm{g})$ is the mass of the magnetic chitosan composite adsorbent.

\subsection{Desorption and reusability experiments}

Reusability is one of the most important features of an adsorbent if it is to have a practical application. To test the reusability of the adsorbent, the adsorption-desorption cycle was repeated 5 times using the same adsorbent. For each cycle, $500 \mathrm{~mL}, 100 \mathrm{mg} / \mathrm{L}$ of $\mathrm{Cu}^{2+}$ solution was adsorbed by $0.05 \mathrm{~g} \mathrm{CsFeAC}$ for $120 \mathrm{~min}$ to reach adsorption equilibrium. The adsorbent loaded with $\mathrm{Cu}^{2+}$ was desorbed using $0.1 \mathrm{M}$ of $\mathrm{Na}_{2}$-EDTA solution, and then washed thoroughly with distilled water for re-adsorption.

\section{Results and discussion}

\subsection{Characterization of magnetic chitosan composite adsorbent}

\subsubsection{SEM and BET analysis}

The surface morphologies of $\mathrm{AC}, \mathrm{Fe}_{3} \mathrm{O}_{4}, \mathrm{FeAC}$ and $\mathrm{CsFeAC}$ characterized by SEM are shown in Fig. 1. It can be seen from Fig. 1c that the porous activated carbon powders (Fig. 1a) and $\mathrm{Fe}_{3} \mathrm{O}_{4}$ crystals (Fig.1b) in FeAC are covered and connected by a loose silica layer, which can protect $\mathrm{Fe}_{3} \mathrm{O}_{4}$ from acidic and oxidative conditions. Moreover, the silica precipitated from $\mathrm{Na}_{2} \mathrm{SiO}_{3} \cdot 9 \mathrm{H}_{2} \mathrm{O}$ contains a certain amount of hydroxide, which may be used to load more chitosan. Interestingly, compared with FeAC in Fig. 1c, the surfaces of $\mathrm{CsFeAC}$ in Fig. 1d look much tighter and 
smoother (Fig. 1d) after loading chitosan onto FeAC, which indicates that the chitosan is successfully cross-linked to the composite carriers. The SEM images reveal that the size of the carriers and adsorbents ranged from a few to tens of micrometers. However, the particle size recorded by SEM is a little smaller than that detected by a laser particle size analyzer. As tested by a laser particle size analyzer, the average particle size of AC and FeAC are 15.72 and $16.22 \mu \mathrm{m}$, respectively, indicating that coating of silica does not significantly change the morphology and size of FeAC. However, the magnetic property of FeAC especially facilitates the magnetic separation process. BET specific surface area of CsFeAC is about $27.97 \mathrm{~m}^{2} / \mathrm{g}$, much larger than those reported in the literature (Meng et al., 2015; Xu et al., 2015), which should be attributed to the larger specific surface area of AC. Hence more chitosan loading and better adsorption capacity is expected.
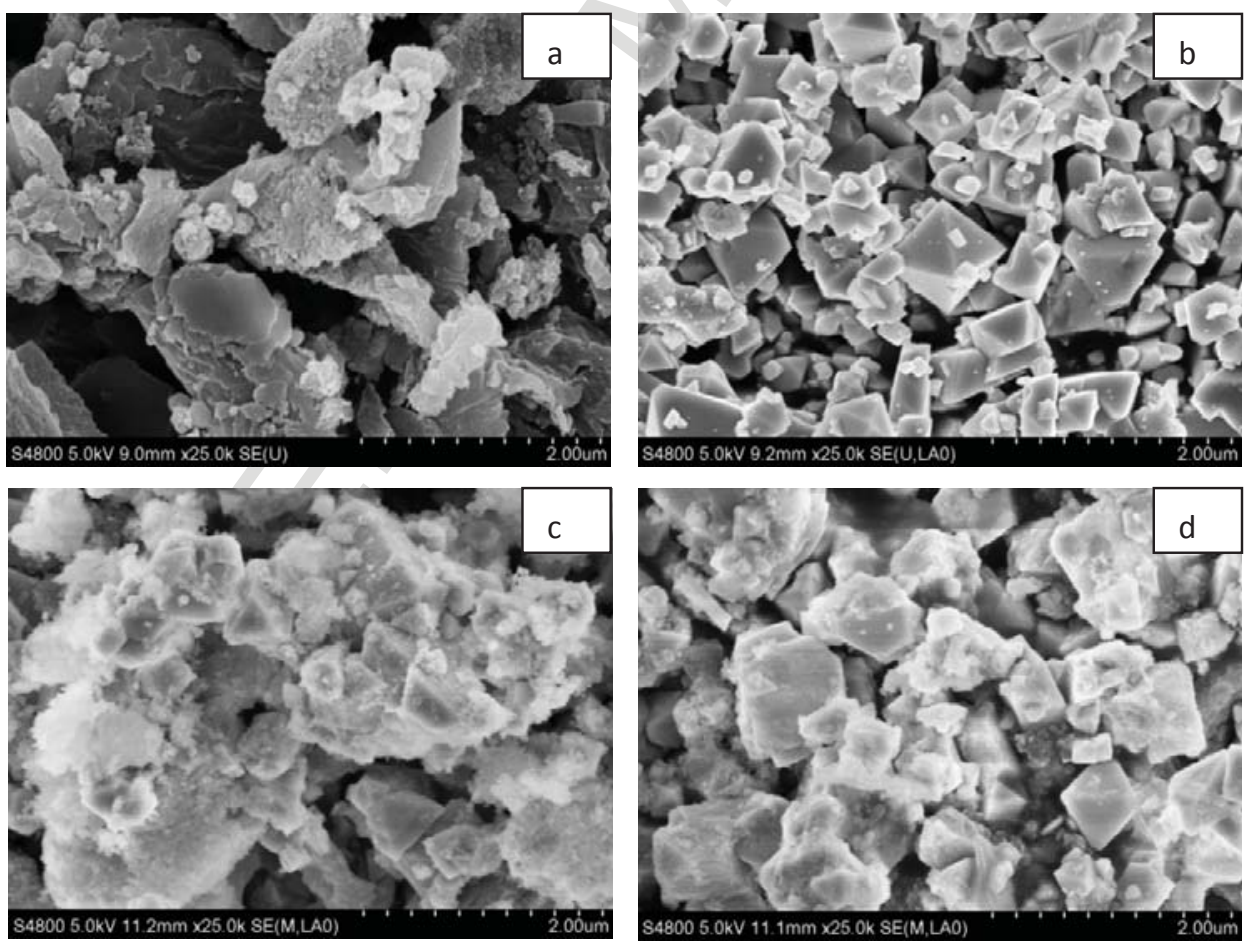

Fig. 1 SEM images of (a) AC, (b) $\mathrm{Fe}_{3} \mathrm{O}_{4}$, (c) $\mathrm{FeAC}$ and (d) $\mathrm{CsFeAC}$ 


\subsubsection{TGA and XRD analysis}

The TGA and DTG curves of AC, FeAC, Cs and CsFeAC are illustrated in Fig. 2. For the TGA results, apart from water loss events, the main chains of cross-linked CsFeAC began to degrade rapidly at $185{ }^{\circ} \mathrm{C}$, and the final decomposition temperature was approximately $650{ }^{\circ} \mathrm{C}$. However, the main chains of $\mathrm{Cs}$ began to degrade rapidly at $260{ }^{\circ} \mathrm{C}$. The difference in decomposition thermograms between $\mathrm{Cs}$ and $\mathrm{CsFeAC}$ suggests that the introduction of magnetic composite carriers into the complex reduces crystallinity, which in turn reduces the degradation temperature (Reddy et al., 2013). This is further confirmed by the XRD patterns in Fig. 3. When comparing the weight losses of $\mathrm{AC}, \mathrm{FeAC}$ and $\mathrm{Cs}$ with $\mathrm{CsFeAC}$, the average mass contents of chitosan, activated carbon, and residual inorganic component in cross-linked CsFeAC are estimated to be $40.07 \%$, $14.28 \%$ and $45.65 \%$, respectively.
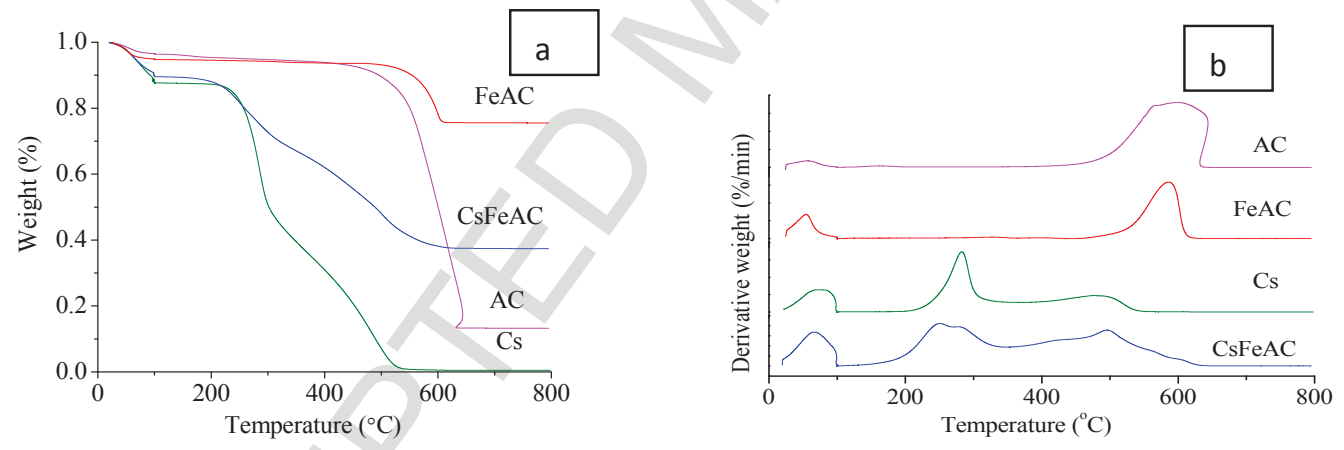

Fig. 2 (a) TGA and (b) DTG curves for AC, FeAC, Cs and CsFeAC
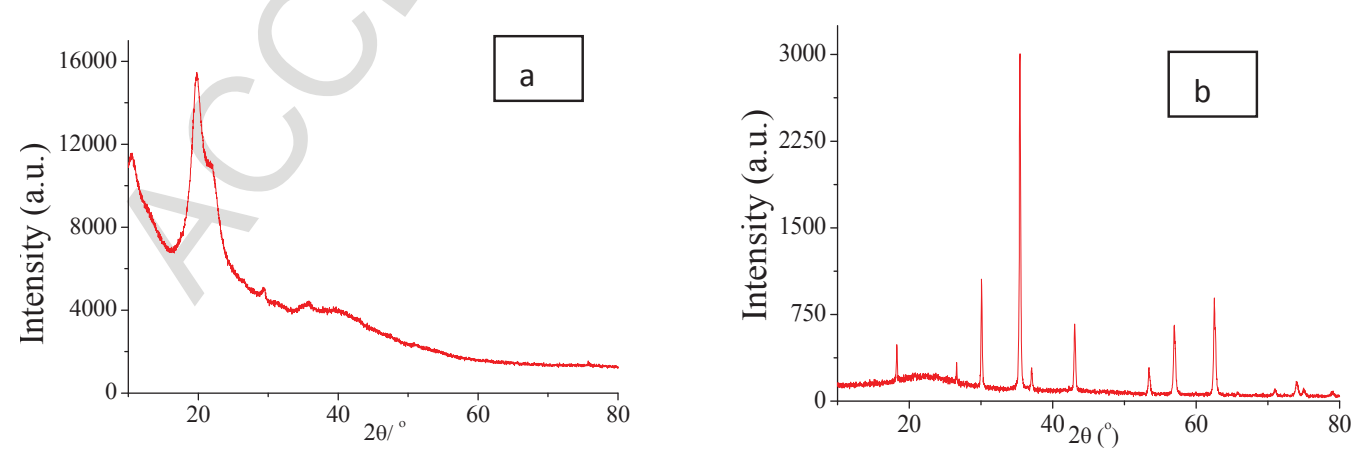

Fig. 3 XRD patterns of (a) Cs and (b) CsFeAC 
The XRD patterns of Cs and CsFeAC are given in Fig. 3. It can be seen that the characteristic diffraction peaks of $\mathrm{Fe}_{3} \mathrm{O}_{4}$ almost appeared in $\mathrm{CsFeAC}$ at $18.3^{\circ}, 30.1^{\circ}, 35.5^{\circ}, 37.1^{\circ}, 43.1^{\circ}, 53.5^{\circ}$, $57.0^{\circ}, 62.6^{\circ}, 71.0^{\circ}, 74.0^{\circ}$ and $75.0^{\circ}$, which could be assigned to the planes in PDF No. 65-3107, and ascribed to cubic spinel phase. This indicated that $\mathrm{CsFeAC}$ contained $\mathrm{Fe}_{3} \mathrm{O}_{4}$ and that no phase change took place. At the same time, the intensive characteristic diffraction peak of Cs at $20.6^{\circ}$ in Fig. 3 (a) almost disappeared in the CsFeAC profile in Fig. 3 (b), suggesting that the crystallization of chitosan was almost unfolded on the magnetic carriers and the amorphous region increased. Consequently, the adsorption capacity of adsorbent was significantly improved, since it was reported that the metal ions more easily penetrated the amorphous region and subsequently adsorbed onto the adsorbent. Similar results have been reported by Luo et al. (2015) and Zhou et al. (2005).

\subsubsection{Magnetic properties analysis}

The magnetic hysteresis loops of $\mathrm{Fe}_{3} \mathrm{O}_{4}, \mathrm{FeAC}$ and $\mathrm{CsFeAC}$ are indicated in Fig. 4. Virtually no

remanence and coercivity was evident in any of them, which indicated the existence of supermagnetic properties. The saturation magnetization of $\mathrm{Fe}_{3} \mathrm{O}_{4}, \mathrm{FeAC}$ and $\mathrm{CsFeAC}$ were 92.60 $\mathrm{emu} / \mathrm{g}, 33.02 \mathrm{emu} / \mathrm{g}$ and $28.32 \mathrm{emu} / \mathrm{g}$, respectively. It is obvious that the loss of saturation magnetization is almost completely in the process of the synthesis of FeAC, and slightly in the chitosan loading of CsFeAC. The saturation magnetization of FeAC declined steeply because of the uniform coating of silica dioxide and the connected $\mathrm{AC}$ carrier around the $\mathrm{Fe}_{3} \mathrm{O}_{4}$, and the saturation magnetization of CsFeAC slightly declined because of the further loading of chitosan. Despite this difference, CsFeAC still could be easily separated from water by magnet.

Interestingly, it is found that the presence of magnetite favors the adsorption of $\mathrm{Cu}^{2+}$. As tested 
by batch experiments using identical conditions, the equilibrium adsorption capacity of $\mathrm{CsFeAC}$ for $\mathrm{Cu}^{2+}$ is $117 \mathrm{mg} / \mathrm{g}$, higher than that of CsAC (chitosan-activated carbon) with $107 \mathrm{mg} / \mathrm{g}$, even though BET specific surface area of CsFeAC is only $27.97 \mathrm{~m}^{2} / \mathrm{g}$, lower than that of CsAC with $107.59 \mathrm{~m}^{2} / \mathrm{g}$. Also, as detected by a laser particle size analyzer, CsAC and CsFeAC have similar particle sizes, $45.90 \mu \mathrm{m}$ and $47.59 \mu \mathrm{m}$, respectively. It can be inferred from this that the magnetic induction may have a positive effect on the $\mathrm{Cu}^{2+}$ adsorption process. The induction mechanism will be further investigated in our future research.

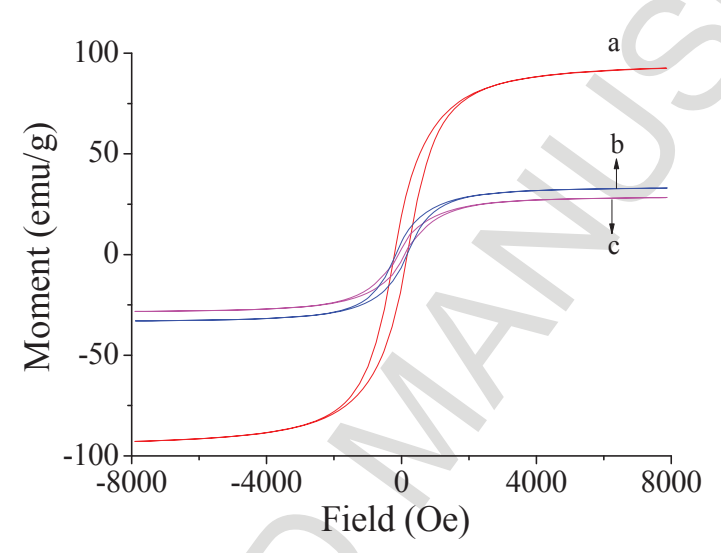

Fig. 4 Magnetic hysteresis loops of (a) $\mathrm{Fe}_{3} \mathrm{O}_{4}$, (b) $\mathrm{FeAC}$ and (c) $\mathrm{CsFeAC}$

\subsubsection{FTIR analysis}

The FTIR spectra of $\mathrm{Cs}, \mathrm{CsFeAC}$ and $\mathrm{Cu}^{2+}$-loaded $\mathrm{CsFeAC}$ are presented in Fig. 5. For chitosan, the broad characteristic peak around $3355 \mathrm{~cm}^{-1}$ is attributed to $\mathrm{O}-\mathrm{H}$ stretching vibration due to the intra- and inter- hydrogen bond, and the peaks at $2919 \mathrm{~cm}^{-1}$ and $2876 \mathrm{~cm}^{-1}$ derive from the stretching vibrations of $\mathrm{C}-\mathrm{H}$ bond. The characteristic peak of primary amine $\left(-\mathrm{NH}_{2}\right)$ appears at $3355 \mathrm{~cm}^{-1}$ for stretching vibration, and the characteristic peaks appear at $1597 \mathrm{~cm}^{-1}$ and $1660 \mathrm{~cm}^{-1}$ for bending vibration. The bands at $1075 \mathrm{~cm}^{-1}$ and $1033 \mathrm{~cm}^{-1}$ display the stretch vibration of C-O bond. Compared to the spectrum of Cs, the typical peaks around $576 \mathrm{~cm}^{-1}$ and $1087 \mathrm{~cm}^{-1}$ correspond to Fe-O stretching vibration and $\mathrm{Si}-\mathrm{O}-\mathrm{Si}$ stretching vibration, respectively. This means 
that $\mathrm{CsFeAC}$ contains silicon and iron oxide. Also, the characteristic peaks at $1597 \mathrm{~cm}^{-1}$ and 1660 $\mathrm{cm}^{-1}$ disappear in CsFeAC, and a broad peak at $1631 \mathrm{~cm}^{-1}$ appears, which may be assigned to the $\mathrm{NH}_{2}$ bending vibration and the $\mathrm{C}=\mathrm{N}$ bond generated from the cross-linking of chitosan with glutaraldehyde. Moreover, the absorption peak at $1384 \mathrm{~cm}^{-1}$ is significantly enhanced, the peak at $2876 \mathrm{~cm}^{-1}$ shifts to $2927 \mathrm{~cm}^{-1}$, and the broad peak of $-\mathrm{NH}_{2}$ and $\mathrm{O}-\mathrm{H}$ shifts from $3355 \mathrm{~cm}^{-1}$ to 3413 $\mathrm{cm}^{-1}$ and becomes narrow. This suggests two things: firstly, that the intra- and inter-hydrogen bonds decrease; and secondly, the free amine and hydroxyl groups increase, which leads to better absorption capacity.

After adsorption of $\mathrm{Cu}^{2+}$, the peak at $1631 \mathrm{~cm}^{-1}$ corresponded to the vibration of $-\mathrm{NH}_{2}$ shifts from $1631 \mathrm{~cm}^{-1}$ to $1636 \mathrm{~cm}^{-1}$, and the peak at $3355 \mathrm{~cm}^{-1}$ corresponded to the stretching vibration of -OH shifts from $3355 \mathrm{~cm}^{-1}$ to $3423 \mathrm{~cm}^{-1}$. Indicated here is that both $-\mathrm{NH}_{2}$ and $-\mathrm{OH}$ play a role in $\mathrm{Cu}^{2+}$ adsorption. Similar results have been reported in other studies (Luo et al., 2015; Chen and Wang, 2011).

(a)

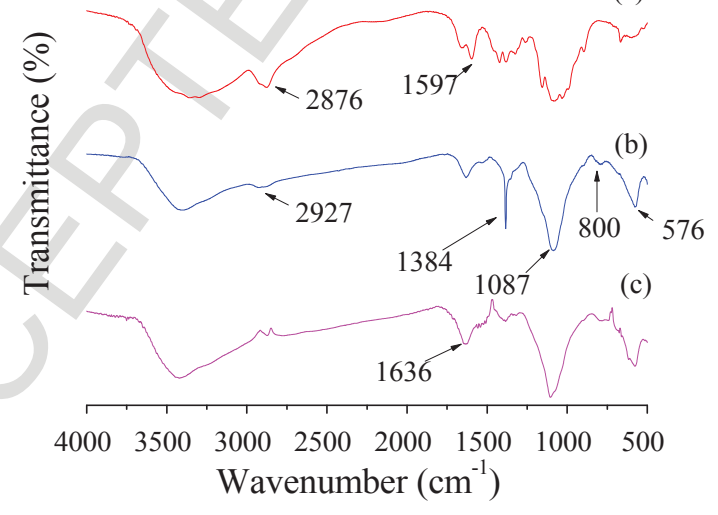

Fig. 5 FTIR spectra of (a) Cs, (b) CsFeAC, and (c) $\mathrm{Cu}^{2+}$-loaded CsFeAC

\subsection{Adsorption properties of $\mathrm{CsFeAC}$ for removing $\mathrm{Cu}^{2+}$}

\subsubsection{Effect of initial pH on the adsorption}

It is confirmed that the solution $\mathrm{pH}$ value makes a significant impact on the adsorption process, 
because it affects not only protonation of functional groups in the adsorbent, but also the precipitation formation of heavy metal ions (Ren et al., 2013; Meng et al., 2015; Chen and Wang, 2011). Considering the formation of $\mathrm{Cu}^{2+}$ hydroxide precipitate at higher $\mathrm{pH}$ value, the selected $\mathrm{pH}$ values in the batch experiments were set below 6.0 in this study. Also, the adsorption capacity of $\mathrm{CsFeAC}$ for $\mathrm{Cu}^{2+}$ ions was investigated at the $\mathrm{pH}$ range of 4-6. It is found that the $\mathrm{Cu}^{2+}$ adsorption capacity of CsFeAC increases from $72 \mathrm{mg} / \mathrm{g}$ to $117 \mathrm{mg} / \mathrm{g}$ with the initial $\mathrm{pH}$ increases from 4.0 to 5.5 and decreases to $96 \mathrm{mg} / \mathrm{g}$ when the initial $\mathrm{pH}$ was 6.0 . The optimal $\mathrm{pH}$ value for $\mathrm{Cu}^{2+}$ adsorption of by $\mathrm{CsFeAC}$ is around 5.5.

It is known that the amino and hydroxyl groups of chitosan are easily protonated at lower $\mathrm{pH}$ values, which means that more active sites are occupied by $\mathrm{H}^{+}$ions. Gradually increases the initial solution $\mathrm{pH}$ value, more active sites are deprotonated, and the positive charge is reduced, which in turn results in better affinity to $\mathrm{Cu}^{2+}$ and consequently higher adsorption capacity. Further increases the $\mathrm{pH}$ value, hydroxide precipitate appears, and correspondingly the adsorption capacity declines. Thus, the $\mathrm{pH}$ value of 5.5 was selected for the following absorption studies.

\subsubsection{Adsorption isotherms}

The adsorption curves at different $\mathrm{Cu}^{2+}$ concentrations are shown in Fig. 6. It can be seen that the adsorption capacity of CsFeAC increased sharply at first with the increase of initial $\mathrm{Cu}^{2+}$ concentrations, and then gently rose to reach a plateau. Furthermore the adsorption capacity almost reached its maximum value at the initial $\mathrm{Cu}^{2+}$ concentration of $500 \mathrm{mg} / \mathrm{L}$, and the $\mathrm{Cu}^{2+}$ adsorption capacity was approximately $200 \mathrm{mg} / \mathrm{g}$. In order to investigate the adsorption mechanism, three isotherms, specifically the Langmuir, Freundlich and Temkin models, are used to match the experimental results. 


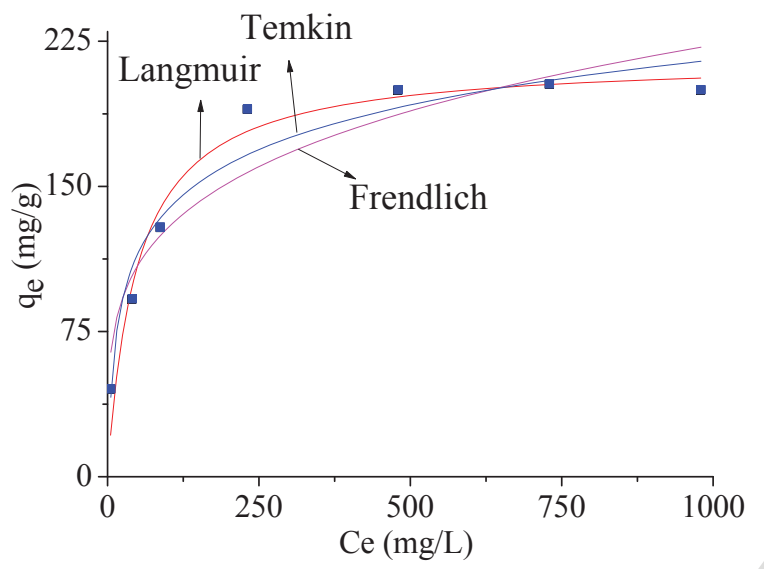

Fig. 6 Adsorption isotherms for $\mathrm{Cu}^{2+}$ on $\mathrm{CsFeAC}$

The Langmuir isotherm assumes that monolayer adsorption occurs on a structurally and energetically homogeneous surface on which the adsorbed molecules on the binding sites are not interactive. Also, the adsorption enthalpy is identical to the increase of adsorption amounts. The Langmuir isotherm is described by equation (2) as follows:

$\frac{1}{q_{e}}=\frac{1}{K_{L} q_{m} C_{e}}+\frac{1}{q_{m}}$

where $\mathrm{q}_{\mathrm{e}}(\mathrm{mg} / \mathrm{g})$ is the equilibrium adsorption capacity on the adsorbent; $\mathrm{C}_{\mathrm{e}}(\mathrm{mg} / \mathrm{L})$ is the equilibrium concentration in the solution; $\mathrm{q}_{\mathrm{m}}(\mathrm{mg} / \mathrm{g})$ is the maximum adsorption capacity on the adsorbent; and $\mathrm{K}_{\mathrm{L}}(\mathrm{L} / \mathrm{mg})$ is the constant of the Langmuir model related to the affinity of binding sites.

The Freundlich isotherm describes the adsorption on a structurally and energetically heterogeneous surface on which the adsorbed molecules are interactive and the amounts of adsorbate can increase infinitely when the initial concentration also increases. The Freundlich isotherm is expressed as equation (3):

$\mathrm{q}_{\mathrm{e}}=\mathrm{K}_{\mathrm{F}} \mathrm{C}_{\mathrm{e}}^{\frac{1}{\mathrm{n}_{\mathrm{F}}}}$

where $\mathrm{K}_{\mathrm{F}}$ and $\mathrm{n}_{\mathrm{F}}$ are the Freundlich constants related to adsorption capacity and intensity, 
respectively.

The Temkin isotherm is a modification equation of the Langmuir isotherm. The adsorption enthalpy declined linearly with the increase of adsorption amounts. The Temkin isotherm is described by equation (4).

$\mathrm{q}_{\mathrm{e}}=\alpha \ln \beta+\alpha \ln \mathrm{C}_{\mathrm{e}}$

where $\alpha$ and $\beta$ are constants related to adsorption enthalpy and capacity of the adsorbent.

The obtained parameters for the isotherms are listed in Table 1. It can be seen that the Langmuir model fits better with the experimental data with the higher correlation coefficient $\mathrm{R}^{2}\left(\mathrm{R}^{2}=0.957\right)$. Also, the maximum adsorption capacity $(216.6 \mathrm{mg} / \mathrm{g})$ obtained from the Langmuir isotherm matches well with the maximum experimental adsorption capacity $(203 \mathrm{mg} / \mathrm{g})$. These results suggest that it is a monolayer adsorption process between $\mathrm{CsFeAC}$ and $\mathrm{Cu}^{2+}$. Therefore the $\mathrm{Cu}^{2+}$ adsorption onto $\mathrm{CsFeAC}$ could be attributed to a homogenous distribution of molecules on the binding sites.

Table 1 Parameters of the isotherm models for $\mathrm{Cu}^{2+}$ adsorption on $\mathrm{CsFeAC}$

\begin{tabular}{|c|c|c|c|c|c|c|c|c|c|c|}
\hline \multirow[t]{2}{*}{ Adsorbent } & \multicolumn{4}{|c|}{ Langmuir parameters } & \multicolumn{3}{|c|}{ Freundlich parameters } & \multicolumn{3}{|c|}{ Temkin parameters } \\
\hline & $\mathrm{q}_{\mathrm{m}}(\mathrm{mg} / \mathrm{g})$ & $\mathrm{K}_{\mathrm{L}}(\mathrm{L} / \mathrm{mg})$ & $\mathrm{R}^{2}$ & $\mathrm{R}_{\mathrm{L}}$ & $\overline{\mathrm{K}_{\mathrm{F}}}$ & $\mathrm{n}_{\mathrm{F}}$ & $\mathrm{R}^{2}$ & $\alpha$ & $\beta$ & $\mathrm{R}^{2}$ \\
\hline $\mathrm{CsFeAC}$ & 216.6 & 0.020 & 0.957 & $0.047-0.831$ & 42.91 & 0.2386 & 0.888 & 0.624 & 33.4 & 0.942 \\
\hline
\end{tabular}

In comparison with other chitosan-based adsorbents reported in the literatures, CsFeAC prepared for this study shows higher adsorption capacity (as shown in Table 2), which may be attributed to the higher specific surface area and lower crystallinity of CsFeAC. In fact, CsFeAC performs better in the separation and reuse processes due to its supermagnetic properties. These characteristics of CsFeAC may facilitate its potential application in heavy metal removal or notable metal recovery. 
Table 2 Comparison of adsorption capacity of chitosan-based adsorbents for $\mathrm{Cu}^{2+}$

\begin{tabular}{|c|c|c|c|}
\hline Adsorbent name & $\mathrm{q}_{\mathrm{m}}(\mathrm{mg} / \mathrm{g})$ & Operational conditions & References \\
\hline $\mathrm{XMCS}$ & $34.5^{\mathrm{a}}$ & $25^{\circ} \mathrm{C}, \mathrm{pH} 5.0$ & Zhu et al., 2012 \\
\hline $\mathrm{MA}-\mathrm{CS} / \mathrm{Fe}_{3} \mathrm{O}_{4}$ & $163.9^{\mathrm{a}}$ & $25^{\circ} \mathrm{C}, \mathrm{pH} 5.0,25 \mathrm{~min}$ & Wu et al., 2015 \\
\hline CMS & $31.4^{\mathrm{a}}$ & $25^{\circ} \mathrm{C}, \mathrm{pH} \mathrm{5.0,12 \textrm {h }}$ & Ren et al., 2013 \\
\hline EDCMS & $44.4^{\mathrm{a}}$ & $25^{\circ} \mathrm{C}, \mathrm{pH} 5.0,12 \mathrm{~h}$ & Ren et al., 2013 \\
\hline $\mathrm{SCCH}$ & $18.08^{\mathrm{a}}$ & $25^{\circ} \mathrm{C}, \mathrm{pH} 6.5,5 \mathrm{~h}$ & Zhang et al., 2008 \\
\hline Porous COCB beads & $227.27^{\text {a }}$ & $30^{\circ} \mathrm{C}, \mathrm{pH} 5.0,24 \mathrm{~h}$ & Mi et al., 2015 \\
\hline Non-porous COCB beads & $175.44^{\mathrm{a}}$ & $30^{\circ} \mathrm{C}, \mathrm{pH} 5.0,72 \mathrm{~h}$ & Mi et al., 2015 \\
\hline TMCS & $66.7^{\mathrm{a}}$ & $28^{\circ} \mathrm{C}, \mathrm{pH} 5.0,8 \mathrm{~h}$ & Zhou et al., 2009 \\
\hline $\mathrm{MCCM}$ & $88.21^{\mathrm{a}}$ & $30^{\circ} \mathrm{C}, 80 \mathrm{r}$ & Luo et al., 2015 \\
\hline Chitosan-modified $\mathrm{MnFe}_{2} \mathrm{O}_{4}$ & $65.1^{\mathrm{a}}$ & $\mathrm{pH} 6.5,5 \mathrm{~h}$ & Meng et al., 2015 \\
\hline Magnetic chitosan nanoparticles & $33.7^{\mathrm{a}}$ & $25^{\circ} \mathrm{C}, \mathrm{pH} \mathrm{5.0,4h}$ & Chen and Wang, 2011 \\
\hline $\mathrm{CsFeAC}$ & $216.6^{\mathrm{a}}$ & $25^{\circ} \mathrm{C}, \mathrm{pH} 5.5,2 \mathrm{~h}$ & This work \\
\hline
\end{tabular}

a Obtained from the Langmuir isothermal model.

Furthermore, the separation factor constant $\left(\mathrm{R}_{\mathrm{L}}\right)$ is introduced to indicate the favorability of CsFeAC towards $\mathrm{Cu}^{2+}$ ions. It is calculated by equation (5):

$\mathrm{R}_{\mathrm{L}}=1 /\left(1+\mathrm{K}_{\mathrm{L}} \mathrm{C}_{0}\right)(5)$

where $\mathrm{K}_{\mathrm{L}}(\mathrm{L} / \mathrm{mg})$ is the Langmuir constant; $\mathrm{C}_{0}(\mathrm{mg} / \mathrm{L})$ is the initial concentration of $\mathrm{Cu}^{2+}$ ions; and $\mathrm{R}_{\mathrm{L}}$ is the separation factor constant of Langmuir isotherm.

$R_{L}$ represents the type of the adsorption that is irreversible $\left(R_{L}=0\right)$, favorable $\left(0<R_{L}<1\right)$, linear $\left(\mathrm{R}_{\mathrm{L}}=1\right)$, or unfavorable $\left(\mathrm{R}_{\mathrm{L}}>1\right)(\mathrm{Xu}$ et al., 2015). As shown in Table 2, the obtained value falls between 0 and 1 , suggesting the adsorption of $\mathrm{CsFeAC}$ for $\mathrm{Cu}^{2+}$ is a favorable reaction.

\subsubsection{Adsorption kinetics}

The effect of contact time on the adsorption of $\mathrm{Cu}^{2+}$ by $\mathrm{CsFeAC}$ is given in Fig. 7. It is 
observed the adsorption is fast initially, slows down thereafter, and finally reaches equilibrium.

Fig. 8 highlights the fact that the adsorption amount at 5 min reached $77 \%$ of the equilibrium amount at $120 \mathrm{~min}$. The initial rapid adsorption may be due to the existence of many vacant adsorption sites on the adsorbent surface. Then this adsorption decreases since the adsorption sites are occupied by $\mathrm{Cu}^{2+}$, until the adsorption reaches equilibrium.

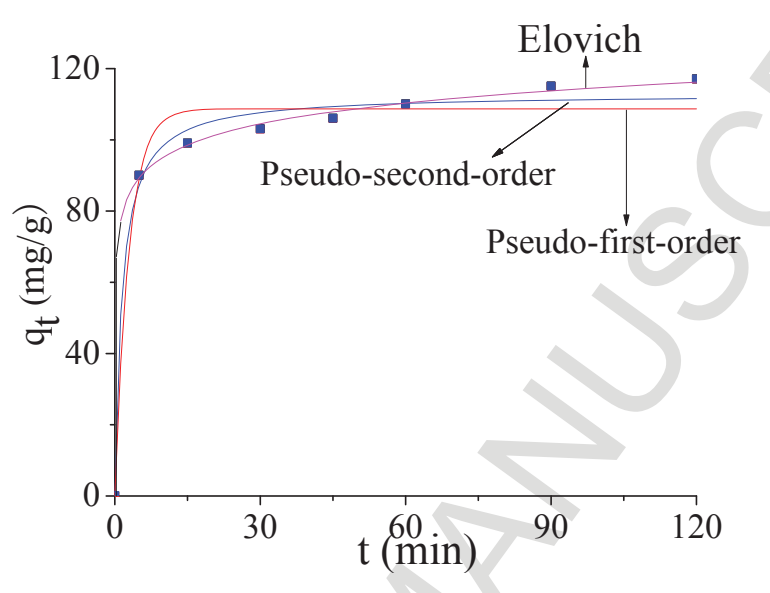

Fig. 7 The adsorption kinetics for $\mathrm{Cu}^{2+}$ adsorption on $\mathrm{CsFeAC}$

It is well-known that the adsorbate first diffuses from solution onto the boundary layer, and then spreads from the boundary layer to the exterior and interior surface of the adsorbent, and finally reacts with the functional groups on the adsorbent. In order to investigate which is the ratelimiting step in the adsorption process, pseudo-first-order, pseudo-second-order, and Elovich models are introduced to fit the experiment data.

The pseudo-first-order, pseudo-second-order, and Elovich models are described as equations (6), (7) and (8), respectively:

$$
\begin{aligned}
& \ln \left(\mathrm{q}_{\mathrm{e}}-\mathrm{q}_{\mathrm{t}}\right)=\ln \mathrm{q}_{\mathrm{e}}-\mathrm{K}_{1} \mathrm{t} \\
& \frac{\mathrm{t}}{\mathrm{q}_{\mathrm{t}}}=\frac{1}{\mathrm{~K}_{2} \mathrm{q}_{\mathrm{e}}^{2}}+\frac{\mathrm{t}}{\mathrm{q}_{\mathrm{e}}} \\
& \mathrm{q}_{\mathrm{t}}=\mathrm{K}_{\mathrm{e}} \ln \mathrm{t}+\mathrm{A}_{\mathrm{e}}
\end{aligned}
$$


where $\mathrm{q}_{\mathrm{t}}(\mathrm{mg} / \mathrm{g})$ and $\mathrm{q}_{\mathrm{e}}(\mathrm{mg} / \mathrm{g})$ represent the adsorption capacity on the adsorbent at time $\mathrm{t}(\mathrm{min})$ and equilibrium, respectively; $\mathrm{K}_{1}, \mathrm{~K}_{2}$ and $\mathrm{K}_{\mathrm{e}}$ are pseudo-first-order kinetics rate constant, pseudosecond-order kinetics rate constant and Elovich kinetics rate constant, respectively; and $A_{e}$ is Elovich kinetics constant.

The parameters calculated from the kinetic models are listed in Table 3. The results indicate that the pseudo-second-order model fits the experiment data much better than the other models, since its correlation coefficient $\left(\mathrm{R}^{2}\right)$ value is 0.990 , which is higher than that of the pseudo-first-order model (0.974) and Elovich model (0.980). Meanwhile, the $\mathrm{q}_{\mathrm{e}}$ value calculated from the pseudosecond-order model is much closer to the experimental data than the other models. These kinetics data imply that the rate-controlling step may be the chemical chelating reaction between $\mathrm{Cu}^{2+}$ ions and binding sites on the adsorbent.

Table 3 Parameters of the kinetic models for $\mathrm{Cu}^{2+}$ adsorption on $\mathrm{CsFeAC}$

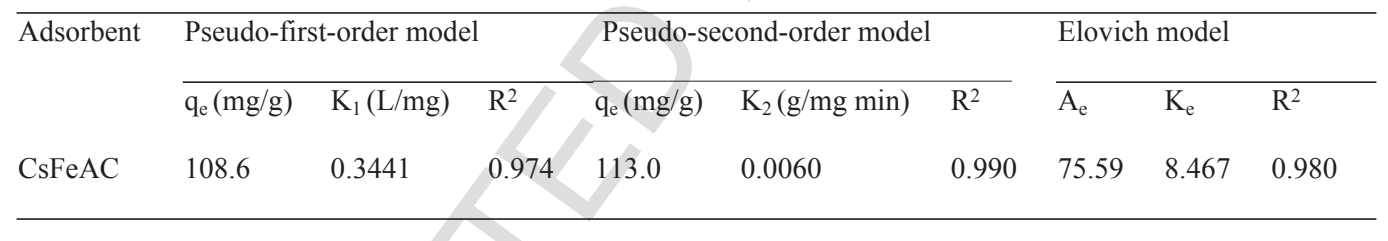

Based on the aforementioned kinetic analysis, it is inferred that the chemical chelating reaction dominates the adsorption of $\mathrm{Cu}^{2+}$ on $\mathrm{CsFeAC}$. This suggests that the exterior and interior diffusion resistances for $\mathrm{Cu}^{2+}$ adsorption are low. The low exterior diffusion resistance may be reduced by shaking the solution sufficiently. The low interior diffusion resistance may be attributed to the chitosan spreading fully on the composite carriers, which results in high specific surface area and low crystallinity of the adsorbent. Consequently, this releases more free amino and hydroxyl groups and improves the adsorption capacity and rate. These results further confirm that it is necessary to increase the specific surface area of adsorbent and decrease the crystallinity of 
chitosan to improve the absorption rate. Added to this, the presence of magnetic species may positively improve the adsorption capacity due to the effect of magnetic induction..

\subsubsection{Adsorption thermodynamics}

The effect of temperature on the adsorption of $\mathrm{Cu}^{2+}$ by CsFeAC is illustrated in Table 4. It is evident that the adsorption capacity increased sharply as the temperature increases from 25 to 55 ${ }^{\circ} \mathrm{C}$, suggesting that the $\mathrm{Cu}^{2+}$ adsorption on $\mathrm{CsFeAC}$ is an endothermic process. Further, the thermodynamic parameters such as the enthalpy change $\left(\Delta \mathrm{H}^{\Theta}\right)$, the entropy change $\left(\Delta \mathrm{S}^{\Theta}\right)$ and the Gibbs free energy change $\left(\Delta \mathrm{G}^{\Theta}\right)$ are calculated by equations (9) - (11), and the results are listed in

Table 4:

$$
\begin{aligned}
& \mathrm{K}_{\mathrm{D}}=\frac{\mathrm{q}_{\mathrm{e}}}{\mathrm{C}_{\mathrm{e}}}(9) \\
& \ln \mathrm{K}_{\mathrm{D}}=-\frac{\Delta \mathrm{H}^{\Theta}}{\mathrm{RT}}+\frac{\Delta \mathrm{S}^{\Theta}}{\mathrm{R}}
\end{aligned}
$$

$\Delta \mathrm{G}^{\Theta}=\Delta \mathrm{H}^{\Theta}-\mathrm{T} \Delta \mathrm{S}^{\Theta}$

where $K_{D}$ is the equilibrium constant; $q_{e}(\mathrm{mg} / \mathrm{g})$ is the equilibrium adsorption capacity on the adsorbent; $\mathrm{C}_{\mathrm{e}}(\mathrm{mg} / \mathrm{L})$ is the equilibrium concentration in the solution; and $\mathrm{R}(8.314 \mathrm{~J} / \mathrm{mol} \mathrm{K})$ and $\mathrm{T}$ (K) are the gas constant and absolute temperature, respectively.

As listed in Table 4, the negative values of $\Delta \mathrm{G}^{\Theta}$ indicate that the adsorption of $\mathrm{Cu}^{2+}$ on $\mathrm{CsFeAC}$ is spontaneous. Also, $\Delta \mathrm{G}^{\Theta}$ decreases with the temperature increasing, which indicates that the adsorption is more favorable at a higher temperature. Furthermore, the positive value of $\Delta \mathrm{H}^{\Theta}$ implies that the adsorption of $\mathrm{Cu}^{2+}$ on $\mathrm{CsFeAC}$ is an endothermic process, and the positive $\Delta \mathrm{S}^{\Theta}$ value suggests an increase in the randomness at the adsorbent/adsorbate interface. The positive values of $\Delta S^{\Theta}$ may be connected to the liberation of protons in the interaction between $\mathrm{Cu}^{2+}$ ions 
and adsorption points. Similar results have been observed in the adsorption of $\mathrm{Pb}^{2+}$ onto carboxylated chitosan magnetic microspheres and submicrospheres (Xu et al., 2015).

Table 4 Thermodynamic parameters for $\mathrm{Cu}^{2+}$ adsorption on $\mathrm{CsFeAC}$

\begin{tabular}{llllll}
\hline $\mathrm{t}\left({ }^{\circ} \mathrm{C}\right)$ & $\mathrm{q}_{\mathrm{e}}(\mathrm{mg} / \mathrm{g})$ & $\mathrm{K}_{\mathrm{D}}$ & $\Delta \mathrm{H}^{\Theta}(\mathrm{kJ} / \mathrm{mol})$ & $\Delta \mathrm{S}^{\Theta}(\mathrm{J} / \mathrm{mol} \mathrm{K})$ & $\Delta \mathrm{G}^{\Theta} /(\mathrm{kJ} / \mathrm{mol})$ \\
\hline 25 & 129 & 1.487 & 17.95 & 63.41 & -0.952 \\
35 & 155 & 1.834 & & -1.586 \\
45 & 186 & 2.285 & & -2.220 \\
55 & 224 & 2.887 & & -2.854 \\
\hline
\end{tabular}

\subsection{Desorption and reusability studies}

Desorption and reusability of an adsorbent is significantly important for further practical applications. Generally, the loaded metal ions can be desorbed by eluent, such as acids and chelating agents. In this study, acids may react with $\mathrm{Fe}_{3} \mathrm{O}_{4}$ in the magnetic composite adsorbent, and depress the magnetic separation of the adsorbent. Consequently, $\mathrm{Na}_{2} \operatorname{EDTA}(0.1 \mathrm{M})$ was selected to desorb the loaded $\mathrm{Cu}^{2+}$ on the adsorbent, since it can form a steady complex with metal ions without any damage being done to the adsorbents.

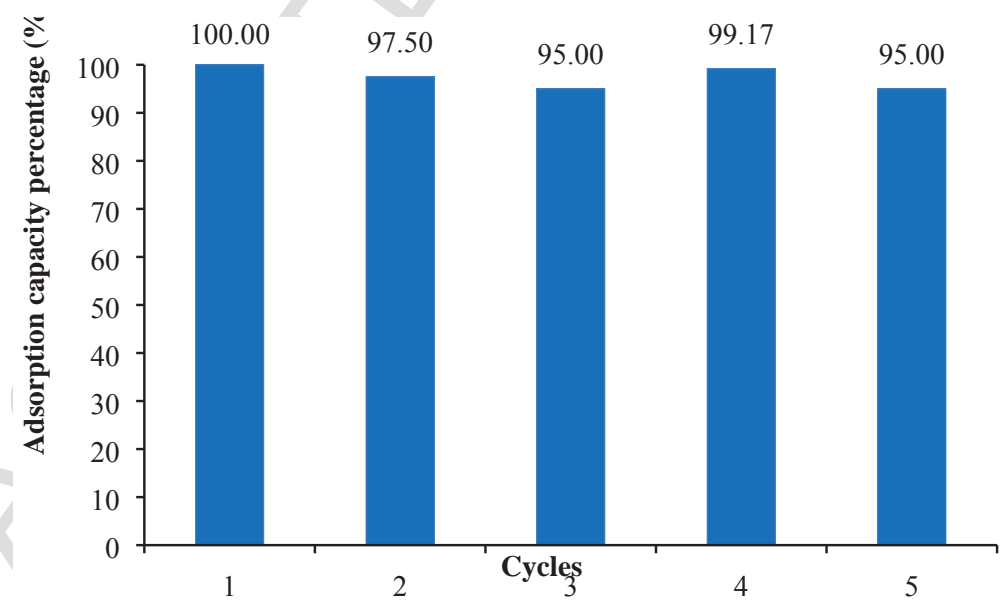

Fig. 8 Reusability of $\mathrm{CsFeAC}$ for $\mathrm{Cu}^{2+}\left(\right.$ initial $\mathrm{Cu}^{2+}$ concentration: $100 \mathrm{mg} / \mathrm{L}$; adsorbent dose: 0.05 $\mathrm{g}$; $\mathrm{pH}$ value: 5.5 ; contact time: adsorption $120 \mathrm{~min}$, desorption $120 \mathrm{~min}$; temperature: $25^{\circ} \mathrm{C}$ ). 
In order to examine the reusability of $\mathrm{CsFeAC}$, the adsorption-desorption cycle was repeated 5 times and the results are presented in Fig. 8. It can be seen that the adsorption capacity of CsFeAC still remains at $95 \%$ at the $5^{\text {th }}$ cycle. These results indicate that desorption of CsFeAC by $\mathrm{Na}_{2}$ EDTA solution is effective, and $\mathrm{CsFeAC}$ has great potential in practical application for $\mathrm{Cu}^{2+}$ removal.

\section{Conclusion}

A cost-effective adsorbent of $\mathrm{CsFeAC}$ was fabricated with micro-scale magnetic activated carbon carrier using the sol-gel method. It is confirmed that the higher specific surface area and lower crystallinity of $\mathrm{CsFeAC}$ significantly improve the absorption capacity. Equilibrium adsorption data fit better with the Langmuir isotherm, suggesting that the adsorption is a monolayer adsorption. Kinetics study indicates that the adsorption follows the pseudo-secondorder model, suggesting that the rate-limiting step is the chemical interaction between $\mathrm{Cu}^{2+}$ and adsorbent. The values of separation constant $\left(0<\mathrm{R}_{\mathrm{L}}<1\right)$ indicate that the adsorption for $\mathrm{Cu}^{2+}$ is a favorable process. FTIR spectra reveal that the amino and hydroxyl groups play an important role in the chelating adsorption. Moreover, its good reusability and convenient magnetic separability enable CsFeAC to potentially have a very beneficial practical application.

\section{Acknowledgements}

The authors appreciate the financial support of the National Natural Science Foundation of China (No. 51408588 and No. 21307093), the Fund for Science and Technology Development of Pudong (PKJ2014-C12), the Shanghai Natural Science Foundation (No. 16ZR1440000), and the 
Youth Innovation Fund for Interdisciplinary Research of SARI (No. Y526453235). The authors are also grateful for the research collaboration among SARI, Shanghai University and UTS.

\section{References}

Ali, I., Gupta, V.K., 2007. Advances in water treatment by adsorption technology. Nat. Protoc. $1(6), 2661-2667$.

Ananpattarachai, J., Kajitvichyanukul, P., 2016. Enhancement of chromium removal efficiency on adsorption and photocatalytic reduction using a bio-catalyst, titania-impregnated chitosan/xylan hybrid film. J. Clean. Prod. 130, 126-136.

Cechinel, M.A.P., Souza, S.M.A.G.U., Souza, A.A.U., 2014. Study of lead (II) adsorption onto activated carbon originating from cow bone. J. Clean. Prod. 65, 342-349.

Chen, H., Deng, C., Zhang, X., 2010. Synthesis of $\mathrm{Fe}_{3} \mathrm{O}_{4} @ \mathrm{SiO}_{2} @$ PMMA core-shell-shell magnetic microspheres for highly efficient enrichment of peptides and proteins for MALDITOF MS analysis. Angew. Chem. Int. Ed. 49, 607-611.

Chen Y.W., Wang J.L., 2011. Preparation and characterization of magnetic chitosan nanoparticles and its application for $\mathrm{Cu}$ (II) removal. Chem. Eng. J. 168, 286-292.

Demiral, H., Güngor, C., 2016. Adsorption of copper (II) from aqueous solutions on activated carbon prepared from grape bagasse. J. Clean. Prod. 124, 103-113.

Elwakeel, K.Z., Atia, A.A., 2014. Uptake of U (VI) from aqueous media by magnetic Schiff's base chitosan composite. J. Clean. Prod. 70, 292-302.

Herrling, M.P., Fetsch, K.L., Delay, M., Blauert, F., Wagner, M., Franzreb, M., Horn, H., Lackner, S., 2015. Low biosorption of PVA coated engineered magnetic nanoparticles in granular sludge assessed by magnetic susceptibility. Sci. Total Environ. 537, 43-50. 
Huang, Y.X., Fulton, A.N., Keller, A.A., 2016. Simultaneous removal of PAHs and metal contaminants from water using magnetic nanoparticle adsorbents, Sci. Total Environ. 571, 1029-1036.

Lara, M.A.M., Blazquez, G. Trujillo, M.C., Perez, A., Calero, M., 2014. New treatment of real electroplating wastewater containing heavy metal ions by adsorption onto olive stone. J. Clean. Prod. 81, 120-129.

Leceta, I., Guerrero, P., Cabezudo, S., Caba, K, 2013. Environmental assessment of chitosanbased films. J. Clean. Prod. 41, 312-318.

Li, Y.H., Jin, Z.H., Li, T.L., Xiu, Z.M., 2012. One-step synthesis and characterization of core shell Fe@ $\mathrm{SiO}_{2}$ nanocomposite for Cr (VI) reduction. Sci. Total Environ. 421-422, 260-266.

Liu, Q., Yang, B.C., Zhang, L.J., Huang, R.H., 2014. Simultaneous adsorption of phenol and $\mathrm{Cu}^{2+}$ from aqueous solution by activated carbon/chitosan composite. Korean J. Chem. Eng. 31(9), $1608-1615$.

Luo, X.G., Zeng, J., Liu, S.L, Zhang, L.N., 2015. An effective and recyclable adsorbent for the removal of heavy metal ions from aqueous system: Magnetic chitosan/cellulose microspheres. Bioresource Technol. 194, 403-406.

Meng, Y.Y., Chen, D.Y., Sun, Y.T., Jiao, D.L., Zeng, D.C., Liu, Z.W., 2015. Adsorption of $\mathrm{Cu}^{2+}$ irons using chitosan-modified magnetic Mn ferrite nanoparticles synthesized by microwaveassisted hydrothermal method. Appl. Surf. Sci. 324, 745-750.

Mi, F.-L., Wu, S.-J., Lin, F.-M., 2015. Adsorption of copper (II) ions by a chitosan-oxalate complex biosorbent. Int. J. Biol. Macromol. 72, 136-144.

Nasirimoghaddam, S., Zeinali, S., Sabbaghi, S., 2015. Chitosan coated magnetic nanoparticles as 
nano-adsorbent for efficient removal of mercury contents from industrial aqueous and oily samples. J. Ind. Eng. Chem. 27, 79-87.

Nitayaphat, W., Jintakosol, T., 2015. Removal of silver (I) from aqueous solutions by chitosan/bamboo charcoal composite beads. J. Clean. Prod. 87, 850-855.

Reddy, D.H.K., Lee, S.-M., 2013. Application of magnetic chitosan composites for the removal of toxic metal and dyes from aqueous solutions. Adv. Colloid Interface Sci. 201-202, 68-93.

Ren, Y., Abbood, H.A., He, F.B., Peng, H., Huang, K.X., 2013. Magnetic EDTA-modified chitosan $/ \mathrm{SiO}_{2} / \mathrm{Fe}_{3} \mathrm{O}_{4}$ adsorbent: Preparation, characterization, and application in heavy metal adsorption. Chem. Eng. J. 226, 300-311.

Tao, X. Li, K., Yan, H., Yang, H., Li, A.M., 2016. Simultaneous removal of acid green 25 and mercury ions from aqueous solutions using glutamine modified chitosan magnetic composite microspheres. Environ. Pollut. 209, 21-29.

Wang, H., Chen, Q.W., Chen, J., Yu, B.X., Hu, X.Y., 2011. Carboxyl and negative charge functionalized superparamagnetic nano chains with amorphous carbon shell and magnetic core: synthesis and their application in removal of heavy metal ions. Nanoscale 3, 4600-4603.

Wang, J., Zheng, S., Shao, Y., Liu, J., Xu, Z., Zhu, D., 2010. Amino-functionalized $\mathrm{Fe}(3) \mathrm{O}(4) @ \mathrm{SiO}(2)$ core-shell magnetic nanomaterial as a novel adsorbent for aqueous heavy metals removal. J. Colloid Interface Sci. 349, 293-299.

Wu, Z.-C., Wang, Z.-Z., Liu, J., Yin, J.-H., Kuang, S.-P., 2015. A new porous magnetic chitosan modified by melamine for fast and efficient adsorption of $\mathrm{Cu}$ (II) ions. Int. J. Biol. Macromol. $81,838-846$.

Xu, Y.Y., Dang, Q.F., Liu, C.S., Yan, J.Q., Fan, B., Cai, J.P., Li J.J., 2015. Preparation and 
characterization of carboxyl-functionalized chitosan magnetic microspheres and submicrospheres for $\mathrm{Pb}^{2+}$ removal. Colloids and Surfaces A: Physicochem. Eng. Aspects 482, 353-364.

Zhang, G., Qu, R., Sun, C., Ji, C., Chen, H., Wang, C., Niu, Y., 2008. Adsorption for metal ions of chitosan coated cotton fiber. J. Appl. Polym. Sci. 110, 2321-2327.

Zhou, D., Zhang, L., Guo, S., 2005. Mechanisms of lead biosorption on cellulose/chitin beads. Water Res. 39(16), 3755-3762.

Zhou, L.M., Wang, Y.P., Liu, Z.R., Huang, Q.W., 2009. Characteristics of equilibrium, kinetics studies for adsorption of $\mathrm{Hg}$ (II), $\mathrm{Cu}(\mathrm{II})$, and $\mathrm{Ni}(\mathrm{II})$ ions by thiourea-modified magnetic chitosan microspheres. J. Hazard. Mater. 161, 995-1002.

Zhu, Y.H., Hu, J., Wang, J.L., 2012. Competitive adsorption of Pb (II), Cu (II) and Zn (II) onto xanthate-modified magnetic chitosan. J. Hazard. Mater. 221-222, 155-161. 